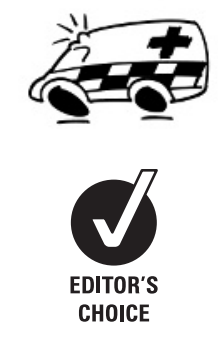

${ }^{1}$ Health Economics and Decision Science, School of Health and Related Research, University of Sheffield, Sheffield, UK; ${ }^{2}$ Health Services Research, School of Health and Related Research, University of Sheffield, Sheffield, UK; ${ }^{3}$ Department of Emergency Medicine, Sheffield Teaching Hospitals Trust, Sheffield, UK;

${ }^{4}$ Centre for Health Information Research and Evaluation, School of Medicine, Swansea University, Swansea, UK;

${ }^{5}$ South Yorkshire Ambulance Service, Rotherham, UK

Correspondence to:

Dr S Dixon, Health Economics and Decision Science, School of Health and Related Research, University of Sheffield, Regent Court, 30 Regent Street,

Sheffield S1 4DA, UK; s.dixon@ sheffield.ac.uk

Accepted 26 October 2008

\title{
Is it cost effective to introduce paramedic practitioners for older people to the ambulance service? Results of a cluster randomised controlled trial
}

\author{
S Dixon, ${ }^{1}$ S Mason, ${ }^{2}$ E Knowles, ${ }^{2}$ B Colwell, ${ }^{2} \mathrm{~J}$ Wardrope, ${ }^{3}$ H Snooks, ${ }^{4}$ R Gorringe, ${ }^{5}$ \\ J Perrin, ${ }^{3} \mathrm{~J}$ Nicholl $^{2}$
}

\section{ABSTRACT}

Background: A scheme to train paramedics to undertake a greater role in the care of older people following a call for an emergency ambulance was developed in a large city in the UK.

Objectives: To assess the cost effectiveness of the paramedic practitioner (PP) scheme compared with usual emergency care.

Methods: A cluster randomised controlled trial was undertaken of PP compared with usual care. Weeks were allocated to the study group at random to the PP scheme either being active (intervention) or inactive (control). Resource use data were collected from routine sources, and from patient-completed questionnaires for events up to 28 days. EQ-5D data were also collected at 28 days. Results: Whereas the intervention group received more PP contact time, it reduced the proportion of emergency department (ED) attendances (53.3\% vs $84.0 \%$ ) and time in the ED (126.6 vs 211.3 minutes). There was also some evidence of increased use of health services in the days following the incident for patients in the intervention group. Overall, total costs in the intervention group were £140 lower when routine data were considered $(p=0.63)$. When the costs and QALY were considered simultaneously, PP had a greater than $95 \%$ chance of being cost effective at $£ 20000$ per QALY.

Conclusion: Several changes in resource use are associated with the use of PP. Given these economic results in tandem with the clinical, operational and patient-related benefits, the wider implementation and evaluation of similar schemes should be considered.

The UK Department of Health has developed a strategy to encourage the increased use of nonmedical staff trained with extended skills to assess and treat patients, a role normally undertaken by doctors. ${ }^{1}$ The introduction of new models of care, including further assessment, triage and treatment skills for paramedics, has been recommended to help manage ever-increasing demands for healthcare. ${ }^{2}$ However, current research evidence concerning safety, effectiveness and costs to support these changes in practice is lacking. ${ }^{3}$

In 2003, the South Yorkshire Ambulance Service (SYAS), UK, developed the Paramedic Practitioner Older People's Support scheme that set out to deliver patient-centred care to older people calling 999 for an ambulance with conditions triaged as not immediately life threatening. Paramedic practitioners (PP) were trained in extended skills to assess and, when possible, treat older people in the community. Operational between the hours of 08:00 and 20:00 each day, the service was activated by a call to the ambulance service or by an ambulance crew attending an eligible patient. We conducted a cluster randomised controlled trial to evaluate this new service. ${ }^{4}$

The use of PP, with extended skills for responding to selected 999 calls relating to elderly patients, could have several important effects on costs and outcomes. The most obvious effects are that PP attendances are anticipated to spend longer at the scene of incidents, yet reduce the number of emergency department (ED) attendances and admissions to hospital. Other potential effects include additional costs of training, equipment and/or the greater use of other services due to the availability of new referral routes to intermediate care schemes, for example. An economic evaluation was therefore undertaken alongside the clinical evaluation to capture these changes in resource use.

In addition to a comparison of costs and benefits relating to normal care and $\mathrm{PP}$ care, a cost-utility analysis was also undertaken. A cost-utility analysis summarises health benefits as qualityadjusted life years (OALY), and the associated incremental cost per OALY ratio can then be used to draw conclusions about value for money.

\section{METHODS}

Patients were eligible for inclusion into the trial if they presented to the ambulance service: with a call originating from a UK Sheffield postcode; between 1 September 2003 and 26 September 2004; between 08:00 and 20:00 hours; were aged 60 years or older; with a presenting complaint that fell within the scope of practice of the PP working within the scheme.

The PP scope of practice was developed to address the needs of patients presenting with falls, lacerations, epistaxis, minor burns and foreign bodies. The additional skills that they possessed included local anaesthetic techniques, wound care, suturing, neurological, cardiovascular and respiratory system examination and protocol-led dispensing.

Cluster randomisation was used for the main trial to reduce the risk of contamination and allow for evaluation at the service level rather than the individual patient level. Weeks were allocated at 
Table 1 Unit costs

\begin{tabular}{|c|c|c|}
\hline Resource & $\begin{array}{l}\text { Unit cost } \\
\text { (£2003/4) }\end{array}$ & Source \\
\hline $\begin{array}{l}\text { PP per minute (within-trial work patterns and } \\
\text { salaries) }\end{array}$ & 1.24 & $\begin{array}{l}\text { SYAS and Sheffield Teaching Hospitals NHS Trust (cost per call } \\
\text { f103) }\end{array}$ \\
\hline $\begin{array}{l}\text { PP per minute (reduced utilisation and ECP } \\
\text { salaries) }\end{array}$ & 2.23 & FRV work patterns and ECP salary (cost per call f186) \\
\hline FRV/motorbike/PTSS per minute & 4.73 & SYAS (cost per call $f 144$ ) \\
\hline Emergency ambulance per minute & 3.53 & SYAS (cost per call $f 182$ ) \\
\hline ED cost per minute & 0.37 & Sheffield Teaching Hospitals NHS Trust \\
\hline MIU attendance & 38 & NHS Reference Costs (discrete MIU) ${ }^{5}$ \\
\hline Hospital social care assessment & 157 & Sheffield Teaching Hospitals NHS Trust ${ }^{*}$ \\
\hline Community social care assessment & 75 & Sheffield Primary Care Trust $\dagger$ \\
\hline Inpatient day in other specialties & Various & Sheffield Teaching Hospitals NHS Trust financial returns 2003/4 \\
\hline Subsequent ambulance attendance & 182 & SYAS \\
\hline Subsequent ED attendance & 57 & $\begin{array}{l}\text { NHS reference costs, ED attendance (no treatment, referred/ } \\
\text { discharged) }\end{array}$ \\
\hline GP visit & 21 & PSSRU $(2004)^{6}$ \\
\hline District nurse visit & 20 & PSSRU $(2004)^{6}$ \\
\hline Social services visit & 36 & PSSRU, intensive case manager for older people ${ }^{6}$ \\
\hline Nursing/residential care day & 52 & PSSRU: $(2004)^{6}$ \\
\hline
\end{tabular}

random before the start of the study, to the PP scheme either being active (intervention), or inactive (control). During inactive weeks, the PP were removed from operational duties within the ambulance service.

\section{Patient recruitment}

PP were central to dispatch and patient recruitment. ${ }^{8}$ During each week, a PP based in the ambulance service control room identified calls eligible for PP assessment by presenting complaint. During intervention weeks, eligible patients were then passed to a PP in the community, whereas during control weeks, patient details were passed to a PP in the ED for followup. All identified patients were approached face to face for written consent to follow-up.

\section{Data collection}

Routine clinical data, including investigations, treatment, diagnoses and outcome relating to the initial patient episode were collected by the research team from the hospitals' patient administration systems, ED and ambulance service records. A postal questionnaire administered at 28 days documented health outcomes using the EQ-5D and subsequent contact with health services. ${ }^{9}$

The EQ-5D is a generic multidimensional quality of life instrument that produces a single score of health-related wellbeing, ranging from -0.6 to 1.0 . Unity represents full health and zero represents death, or a health state considered to be as bad as being dead; negative scores represent health states considered to be worse than death. The EQ-5D score (or "utility") is then multiplied with the length of life measured in years to produce OALY, such that one year spent in full health is 1 OALY.

The economic evaluation followed the technology appraisal guidelines used by the National Institute for Clinical Excellence, and as such takes the National Health Service (NHS) and social service perspective. ${ }^{10}$

\section{Costs}

The following cost components were included in the economic evaluation: PP costs; other emergency responder costs; ED costs;

Table 2 Main trial outcomes

\begin{tabular}{|c|c|c|c|c|c|}
\hline Trial outcomes & $\begin{array}{l}\text { Intervention } \\
\text { weeks } \\
\text { n }(\%)\end{array}$ & $\begin{array}{l}\text { Control weeks } \\
\text { n (\%) }\end{array}$ & $\begin{array}{l}\text { Relative risk } \\
(95 \% \mathrm{Cl})\end{array}$ & p Value & ICC \\
\hline $\begin{array}{l}\text { ED attendance between } 0-28 \text { days } \\
(\mathrm{n}=3018)\end{array}$ & $970(62.6)$ & $1286(87.5)$ & $0.72(0.68$ to 0.75$)$ & $<0.001$ & 0.00 \\
\hline $\begin{array}{l}\text { Hospital admission between } 0 \\
28 \text { days }(\mathrm{n}=3018)\end{array}$ & $626(40.4)$ & $683(46.5)$ & $0.87(0.81$ to 0.94$)$ & $<0.001$ & 0.00 \\
\hline $\begin{array}{l}\text { Patient very satisfied with care } \\
(\mathrm{n}=1482)\end{array}$ & $656(85.5)$ & $528(73.8)$ & $1.16(1.09$ to 1.23$)$ & $<0.001$ & 0.00 \\
\hline \multirow[t]{2}{*}{ Mortality at 28 days $(\mathrm{n}=3018$ ) } & $68(4.4)$ & $74(5.0)$ & $0.87(0.63$ to 1.21$)$ & 0.41 & 0.00 \\
\hline & Mean (SD) & Mean (SD) & Difference (SE, 95\% Cl) & & \\
\hline $\begin{array}{l}\text { Total episode time, minutes } \\
(\mathrm{n}=2968)\end{array}$ & $235.1(183.3)$ & $277.8(182.6)$ & $\begin{array}{l}-42.2(8.8,-59.5 \text { to } \\
-25.0)\end{array}$ & $<0.001$ & - \\
\hline
\end{tabular}


inpatient costs; social care assessments; primary and community care costs; nursing/residential care costs.

Resource use for each of the first five components was collected from routine data. Resource use for primary and community care and nursing/residential care was obtained from the 28-day patient questionnaires. All episodes of care that were initiated within 28 days of the initial 999 call were included in the analysis.

Costs of training PP were based on the time spent by trainers and paramedics for the taught curriculum, supervised practice, study days plus examinations. Based on a 20-year working life after training, an annual equivalent cost of training was calculated using a $3.5 \%$ discount rate. ${ }^{10}$ The total cost of training per paramedic was calculated at $£ 9145$ (2003/4 prices), which produces an equivalent annual cost of $£ 622$. This additional cost was then used in the calculation of the unit costs of a PP call and minute of PP time.

The unit costs (2003/4 prices) are given in table 1 . The main sources of the unit cost data are SYAS, Sheffield Teaching Hospitals, NHS reference costs and "unit costs of health and social care". ${ }^{6}$ Costs were not discounted as they all fell within one year.

\section{Outcomes}

The EQ-5D was administered to patients at 28 days following their initial 999 call. In order to estimate OALY over the month following treatment, an estimate of baseline utility is required. Despite the lack of baseline data, incremental OALY can still be estimated assuming a linear change in EQ-5D scores and that the two groups have identical scores at baseline. EQ-5D scores were estimated using the UK tariff based on time trade-off values. $^{9}$

\section{Analysis}

Mean resource use, cost and OALY were compared between the study groups and confidence intervals around the differences presented. The main focus of the analysis was to plot the costeffectiveness acceptability curve (CEAC) for the intervention and identify the probability that it is cost effective when OALY are valued at $£ 20000$ per annum. The value of $£ 20000$ per OALY is chosen as it is the lower funding threshold used by the National Institute for Clinical Excellence for its technology appraisals. $^{10}$
Sensitivity analyses focused on the unit costs of the PP. The baseline unit cost of $£ 103$ per call (or $£ 1.24$ per minute) is based on paramedic salaries and the high levels of utilisation seen in the trial. If expanded, it is likely that the service would be staffed by emergency care practitioners (ECP) and face lower levels of utilisation. Both of these changes would increase the cost per call. Assuming work patterns similar to those of fast response vehicles (FRV) and staffing by ECP produces a cost per call of $£ 186$ (or $£ 2.23$ per minute).

Continuous data were analysed using the generalised estimating equation command in STATA together with an allowance for clustering by week. An additional set of analyses of total costs and OALY was undertaken using multiple imputation using the NORM package. ${ }^{11}$ Five datasets were imputed, using cluster, ED attendance, admission to hospital, age, gender and place of residence as explanatory variables. Mean differences in costs and CEAC were then calculated from these five datasets.

\section{RESULTS}

Table 2 provides an overview of the main trial results. ${ }^{4}$ There were very few missing data for those cost components gathered using routine data $(0-2.5 \%)$. The intraclass correlation coefficient for total costs is less than 0.00001 . This is probably due to the large number of clusters $(n=56)$, with large numbers of observations within each (minimum 35, maximum 67, mean 51).

\section{Resource use}

Statistically significant differences $(p<0.05)$ were found in all resource use categories in table 3 except for the length of stay for same-day admissions. However, the direction of difference was not uniform. PP time was higher in the intervention group but other responders spent longer with the control group. Control group patients were more likely to go to the ED, spend longer in the ED, be admitted to hospital and spend longer as inpatients. Following these initial episodes of care, intervention patients had more secondary care contacts in the following 28 days and subsequently spent more time in hospital.

When questionnaire data are examined, much higher amounts of missing data are present (57-66\%) with the problem being slightly worse in the control group. These data show (not tabulated) similar patterns of primary and community care utilisation in the 28 days following the initial 999 call and a

Table 3 Resource use for patients available from routine data

\begin{tabular}{|c|c|c|c|}
\hline Item & $\begin{array}{l}\text { Intervention } \\
\mathrm{n}=1549-1510\end{array}$ & $\begin{array}{l}\text { Control } \\
n=1469-1437\end{array}$ & $\begin{array}{l}\text { Mean difference } \\
\text { ( } 95 \% \mathrm{Cl} \text { of the difference) }\end{array}$ \\
\hline PP minutes & 58.3 & 0.0 & $+58.3(+55.9$ to +60.8$)$ \\
\hline Other responder minutes & 43.4 & 65.1 & $-21.7(-24.2$ to -19.3$)$ \\
\hline No of ambulance activations & 1.6 & 1.2 & $+0.4(+0.4$ to +0.4$)$ \\
\hline ED attendance (\%) & 53.3 & 84.0 & $-30.7(-33.7$ to -27.5$)$ \\
\hline Length of time in ED (minutes) & 126.6 & 211.3 & $-84.7(-96.8$ to -72.6$)$ \\
\hline Hospital admission (\%) & 28.1 & 38.2 & $-10.1(-13.4$ to -6.7$)$ \\
\hline $\begin{array}{l}\text { Length of stay for same-day admissions } \\
\text { (days) }\end{array}$ & 7.5 & 9.1 & $-1.6(-3.1$ to +0.1$)$ \\
\hline Hospital social care referrals (\%) & 2.8 & 5.1 & $-2.3(-3.8$ to -0.9$)$ \\
\hline Community social care referrals (\%) & 5.1 & 0.0 & $+5.1(+4.1$ to +6.3$)$ \\
\hline Other secondary care (contacts) ${ }^{*}$ & 0.5 & 0.4 & $+0.1(+0.0$ to +0.2$)$ \\
\hline $\begin{array}{l}\text { Length of stay for subsequent admissions } \\
\text { (days) }\end{array}$ & 3.4 & 2.1 & $+1.3(+0.5$ to +2.2$)$ \\
\hline
\end{tabular}

\footnotetext{
*Includes ambulance attendances, emergency department (ED) attendances and admissions. PP, paramedic practitioner.
} 
Table 4 Health and social care costs per patient with allowance for clustering

\begin{tabular}{|c|c|c|c|c|c|c|}
\hline Item & \multicolumn{3}{|l|}{ Routine data } & \multicolumn{3}{|c|}{$\begin{array}{l}\text { Routine data plus patient reported data of primary/social care } \\
\text { and nursing/residential care }\end{array}$} \\
\hline PP & 73 & 0 & $+73(+70$ to 76$)$ & 73 & 0 & $+73(+68$ to +78$)$ \\
\hline Other responders & 155 & 232 & $-77(-88$ to -66$)$ & 146 & 216 & $-71(-90$ to -51$)$ \\
\hline $\mathrm{ED} / \mathrm{MIU}$ attendance & 46 & 78 & $-32(-38$ to -26$)$ & 39 & 71 & $-32(-41$ to -23$)$ \\
\hline Subsequent secondary care contacts§ & 44 & 38 & $+6(-1$ to +12$)$ & 24 & 29 & $-5(-15$ to +5$)$ \\
\hline Subsequent inpatient stays & 944 & 572 & $+374(+103$ to +644$)$ & 315 & 551 & $-244(-625$ to +136$)$ \\
\hline Subsequent primary and social care costs & - & - & & 39 & 38 & $+2(-5$ to +9$)$ \\
\hline Nursing and residential care costs & - & - & - & 35 & 16 & $+18(-7$ to +43$)$ \\
\hline Total cost & 3966 & 4116 & $-140(-694$ to +415$)$ & 2102 & 2641 & $-551(-1170$ to +67$)$ \\
\hline
\end{tabular}

*Actual means. †Adjusted estimates using the "xtgee" command in STATA. \$Hospital and community social care assessment assessments. §lncludes ambulance attendances and emergency department (ED) attendances. MIU, minor injuries unit; PP, paramedic practitioner.

slightly greater use of nursing/residential care in the intervention group ( +0.4 days, $\mathrm{p}=0.046)$.

\section{Costs}

When costs based on routine data are examined, missing data rates increase slightly to $6.7 \%$ and $4.2 \%$ in the intervention and control groups, respectively. Additional PP costs of $£ 73$ per patient are similar in magnitude to the additional costs of other responders of $£ 77$ per patient in the control group (table 4). Statistically significant differences are also seen in same-day ED costs with the PP group costing £32 less and subsequent inpatient costs with the PP group costing $£ 372$ more. Overall, the PP group cost $£ 140$ less, although this difference is not statistically significant $(p=0.63)$.

When patient-reported cost data relating to primary/community care and nursing/residential care are included, the results change markedly (table 4 ). This is primarily due to changes in inpatient costs that are consistent with the notion that those responding to the 28-day questionnaire were less sick at baseline. Consequently, these costs may incorporate a selection bias.

The sensitivity analysis examined changes in PP unit costs. Assuming PP vehicles have the same level of utilisation as ordinary FRV and are staffed by ECP reduces the mean cost difference such that PP are $£ 92$ less costly (using costs based on routine data).

Missing data rates for the EQ-5D are $58.3 \%$ and $61.3 \%$ in the intervention and control groups, respectively (table 5). EQ-5D scores (or "utility") are slightly higher in the control group, as too are OALY. The OALY advantage in the control group is less than $0.001(p=0.13)$.

Combining cost and OALY data requires the examination of patients with both sets of data and results in a further increase in the missing data rates to $72.7 \%$ and $73.3 \%$ in the intervention and control groups, respectively. Within this complete case analysis, PP are $£ 680$ less costly and produce 0.0003 fewer OALY. The cost-effectiveness acceptability curve indicates that at £20 000 per OALY the PP scheme has a greater than $95 \%$ chance of being cost effective (fig 1).

When missing data are imputed, the mean cost difference of $£ 680$ seen in the complete cases analysis reduces to $£ 162$, which is much more similar to that seen in the analysis of routine data (table 4). This has a large impact on the CEAC, reducing the probability of the scheme being cost effective to $73 \%$ at the funding threshold of $£ 20000$ per OALY.

\section{DISCUSSION}

The study shows statistically significant changes in the use of NHS resources when PP are used. More specialist PP resources are consumed, as too are more community social care assessments and secondary care in the days following the initial 999 call. These are offset, in cost terms, by the reduced use of other ambulances for the initial call, reduced ED and inpatient resources.

The increased use of PP time and reduction in other responders is not surprising, as the intervention is to a large extent a simple substitution of labour. The statistically significant and wide-ranging nature of the other effects is interesting. The biggest of these effects is the reduction in ED attendances and inpatient length of stay. The PP seem to precipitate a greater use of some services in the days following their intervention. Further work examining unplanned hospital attendances has been undertaken by independently assessing patient records and this found that these events were not attributable to the type of care received. ${ }^{12}$

Table 5 EQ-5D and QALY for respondents in the two groups

\begin{tabular}{llll}
\hline Item & $\begin{array}{l}\text { Intervention } \\
\text { Mean } \\
\mathbf{n}=\mathbf{6 4 6}\end{array}$ & $\begin{array}{l}\text { Control } \\
\text { Mean } \\
\mathbf{n}=\mathbf{5 6 8}\end{array}$ & $\begin{array}{l}\text { Mean difference } \\
\text { (95\% Cl of the } \\
\text { difference) }\end{array}$ \\
\hline EQ-5D & 0.484 & 0.513 & $-0.029(-0.068$ to +0.009$)$ \\
CALY over 28 days* & 0.038 & 0.039 & $-0.001(-0.003$ to +0.000$)$ \\
\hline CALY quality-adjusted life years & &
\end{tabular}




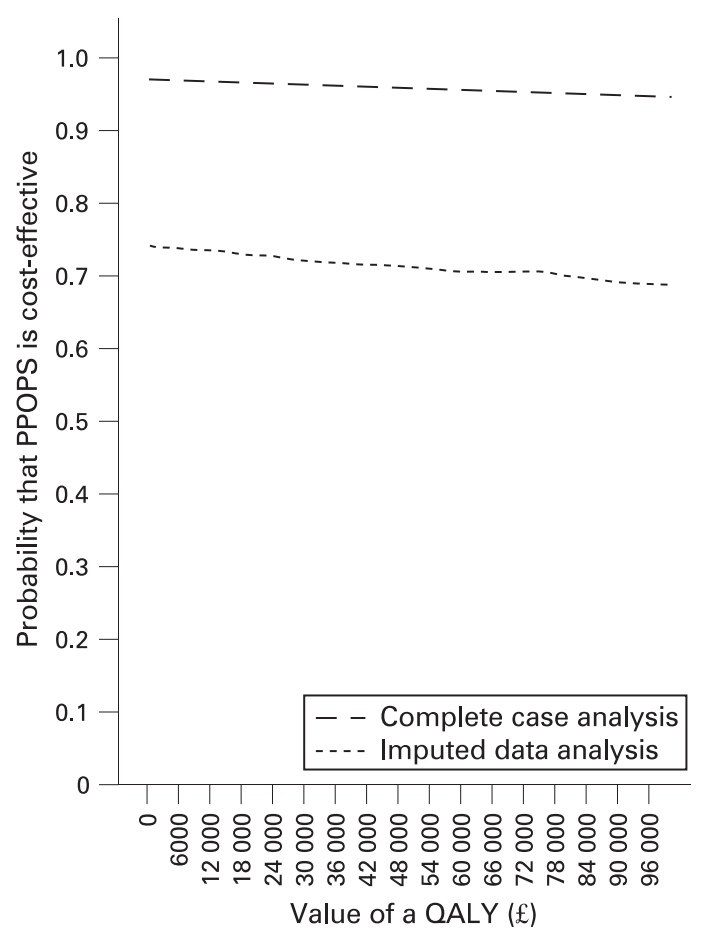

Figure 1 Cost-effectiveness acceptability curves for the paramedic practitioner scheme. PPOPS, Paramedic Practitioner Older People's Support; OALY, quality-adjusted life years.

We must also recognise that this scheme operated in a single area, with the cooperation of a single ambulance service. Hospital trusts and ambulance services may have different work patterns that may have an impact on cost differences. For example, ambulance services that have lower rates of transfer to the ED will have a reduced scope to lower this further with a PP scheme. Such issues of generalisability have been assessed for other emergency care evaluations and need to be considered by potential providers of a PP scheme. ${ }^{13}$

In addition, we should consider whether there are any patient subgroups for which service consequences, and hence cost effectiveness, varies significantly. However, approximately $90 \%$ of the patients presented as a result of a fall, leaving very few observations relating to the other conditions. As a result, subgroup analyses are not informative in this instance.

Whereas the missing data rates for the study questionnaires are similar to other studies in this setting, the differences in the characteristics of the responders make interpretation difficult. ${ }^{14-16}$ Data imputation was used in an attempt to counter this problem, and although this has an impact, it does not change the fundamental finding that the scheme is likely to be cost effective.

The incorporation of the EQ-5D and OALY data is perhaps unnecessary. Some may argue that the difference in QALY is so small that it should be judged as insignificant and therefore not be included in the overall assessment of cost effectiveness. Such an approach was widespread until recently; studies were rebranded cost-minimisation analyses and OALY data were ignored. However, the advent of more advanced analytical techniques, such as cost-effectiveness acceptability curves, has emboldened some economists to argue that no OALY change is too small to ignore. ${ }^{17}$ This latter approach was adopted in this study, but less technical interpretations of the cost data in tandem with the clinical results led to similar conclusions in this instance. $^{4}$
In the context of this study, an important difference in EQ$5 \mathrm{D}$ scores was not expected, and the self-selection that is apparent means that these data are to be used with caution even with the use of imputation. We would argue that these data and the derived cost-per-OALY estimates should be used judiciously in order that the main findings of the study are not obscured.

One final point on the interpretation of the results is worth making. Lower costs in the intervention group should not be equated to "cost savings"; it is almost inconceivable that expenditure will be released by the introduction of PP. However, in operational terms, the additional investment required is offset by generating additional capacity throughout the system, thereby increasing its ability to meet response time performance targets.

\section{CONCLUSION}

Several changes in resource use are associated with the use of PP, which overall amount to a reduced cost of service of $£ 140$ per patient, although this difference is not statistically significant. In tandem with this, the clinical evaluation showed reductions in the episode length, admissions to ED and hospital, and increased patient satisfaction for those patients who responded to the follow-up questionnaire.

Including broader costs (primary and nursing home care) and health outcomes adds some uncertainty due to the selfselected nature of the patient providing these additional data. However, after imputation of missing data, the results appear to reinforce the conclusion that PP are cost effective. In conclusion, given these economic results in tandem with the clinical, operational and patient-related benefits, we would recommend consideration of the wider implementation and evaluation of similar schemes. In particular, further evaluations would allow the generalisability of the results in the face of different admission rates and intermediate care services.

Funding: This study was funded by the Health Foundation (formerly PPP). Competing interests: None.

Ethics approval: Ethics approval was obtained.

\section{REFERENCES}

1. Department of Health. The NHS plan. London: Department of Health, 2001.

2. Department of Health. Taking health care to the patient-transforming NHS ambulance services. London: Department of Health, 2005.

3. Snooks H, Williams S, Crouch R, et al. NHS emergency response to 999 calls: alternatives for cases that are neither life-threatening nor serious. BMJ 2002; $325: 330-3$

4. Mason S, Knowles E, Colwell B, et al. Paramedic Practitioner Older People's Support Trial (PPOPS): a cluster randomised controlled trial. BMJ 2007;335:919-25.

5. Department of Health. NHS reference costs 2004. 7 March 2005. http://www.dh. gov.uk/en/Publicationsandstatistics/Publications/PublicationsPolicyAndGuidance/ DH_4105545 ( accessed 20 March 2008).

6. Netten A, Curtis L. Unit costs of health and social care. University of Kent, Canterbury: Personal Social Services Research Unit, 2004.

7. Netten A, Bebbington A, Darton R, et al. 1996 Survey of care homes for elderly people. Final report. PSSRU discussion paper 1423/2. Canterbury: Personal Social Services Research Unit, 1998.

8. Mason S, Wardrope J, Perrin J. Developing a community paramedic practitioner intermediate care support scheme for older people with minor conditions. Emerg Med J 2003;20:196-8.

9. Dolan P. Modeling valuations for Euro0ol health states. Med Care 1997;35:1095-108.

10. National Institute for Clinical Excellence. Guide to the methods of technology appraisal. London: NICE, 2004.

11. Schafer JL. Analysis of incomplete multivariate data. London: Chapman and Hall, 1997. 
12. Mason S, Knowles E, Freeman J, et al. Safety of paramedics with extended skills. Acad Emerg Med 2008;15:607-12.

13. Goodacre S, Dixon S. Is a chest pain observation unit likely to be cost-effective at my hospital? Extrapolation of data from a randomised controlled trial. Emerg Med J 2005;22:418-22

14. Turner J, Nicholl J, Webber L, etal. A randomised controlled trial of prehospital intravenous fluid replacement therapy in serious trauma. Health Technol Assess 2000;4:(31).
15. Nicholl J, Hughes S, Dixon S, et al. The costs and benefits of paramedic skills in prehospital trauma care. Health Technol Assess 1998;2:(17).

16. Turner J, Snooks H, Youren A, et al. The costs and benefits of managing some low priority 999 ambulance calls by NHS direct nurse advisers. London: National Coordination Centre for Service Delivery and Organisation, 2006.

17. Briggs AH, O'Brien BJ. The death of cost-minimisation analysis? Health Econ 2001;10:179-84.

\section{Images in emergency medicine}

\section{Beware the tree of heaven! (Ailanthus altissima)}

A 32-year-old tree surgeon presented to the emergency department with an 8-day history of a skin rash, which developed after he was exposed to the sap of the "tree of heaven" at work.

On examination he had a well-demarcated, urticarial, erythematous rash with multiple excoriations on both his forearms (see fig 1). He was discharged home on piriton, with a likely diagnosis of contact dermatitis, after discussion with the National Poisons Centre.

$\mathrm{He}$ then re-presented within $48 \mathrm{~h}$ with spreading of the rash to his genitals, lower abdomen and thighs. He remained systemically well. He was referred to the dermatologists who treated him with a reducing regime of steroids, fusidic cream and dermovate, and the rash resolved within 30 days.

The tree of heaven was brought to Britain from its native China in 1751, and is rapidly spreading throughout the UK (see fig 2.)

A recent case report describes how a patient presented with myocarditis after being exposed to the sap through ruptured blisters on his skin. ${ }^{1}$

There is only one other documented case of contact dermatitis after exposure to the sap, and in that case the patient's rash was also successfully treated with topical steroids and antihistamines. ${ }^{2}$

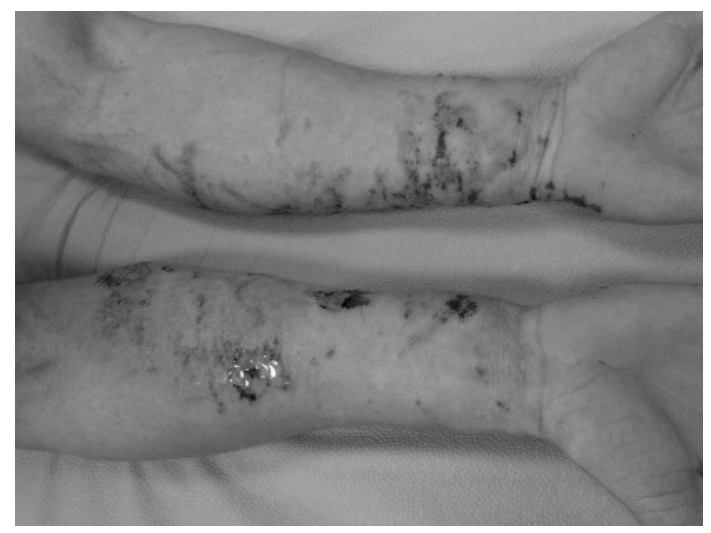

Figure 1 Rash present on patient's forearms on initial presentation to the emergency department.

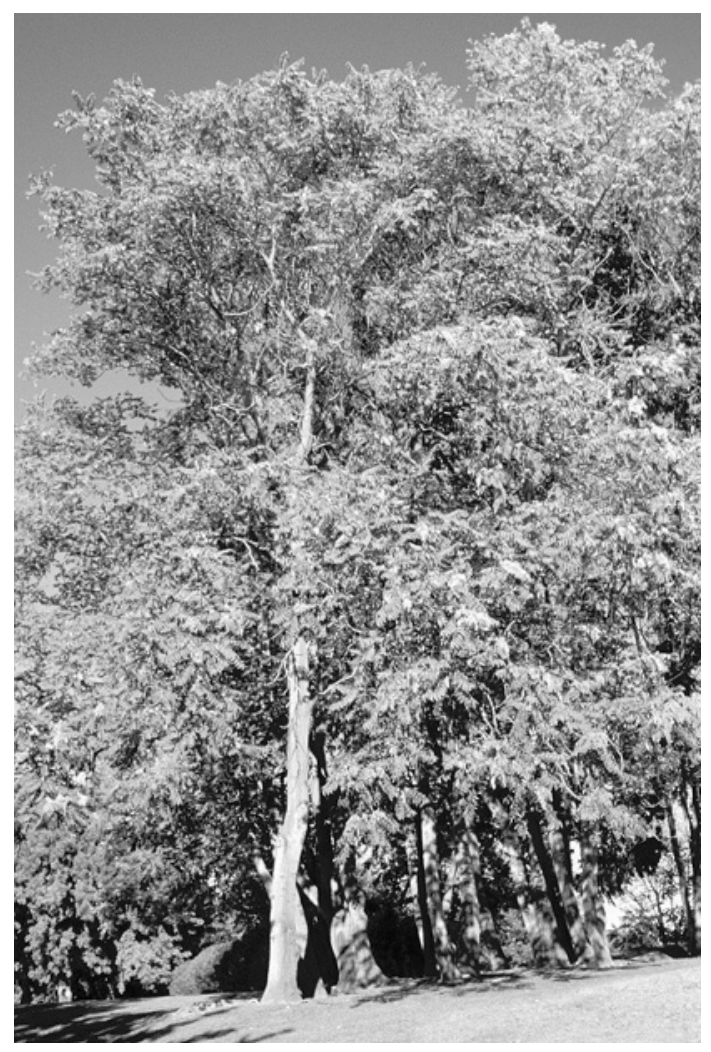

Figure 2 Tree of heaven (Ailanthus altissima)

\section{R Whiticar, C Harvey}

Emergency Department, Wycombe General Hospital, Reading, UK

Correspondence to: Dr R Whiticar, Emergency Department, Wycombe General Hospital, 20 Cadugan Place, Addington Road, Reading RG1 5PN, UK; rwhiticar@ doctors.org.uk

\section{Competing interests: None.}

Patient consent: Obtained.

Emerg Med J 2009;26:451. doi:10.1136/emj.2008.064808

\section{REFERENCES}

1. Bisognano JD, McGrody KS, Spence AM. Myocarditis from the Chinese sumac tree. Ann Intern Med 2005;143:159-60.

2. Derrick EK, Darley CR. Contact reaction to the tree of heaven. Contact Dermatitis 1994;30:178. 